\title{
Suppressive Activity of Chondroitin Sulfate on Periostin Production by Synoviocytes from Knee Osteoarthritis In Vitro
}

Daisuke Tamaki ${ }^{1}$, Shintaro Ishikawa ${ }^{2}$, Asako Yamada ${ }^{3}$, Amane Otaki ${ }^{1}$, and Kazuhito Asano ${ }^{4^{*}}$
${ }^{1}$ Graduate School of Health Sciences, Showa University Graduate School, Yokohama, Japan
${ }^{2}$ Department of Physiology, School of Medicine, Showa University, Tokyo, Japan
${ }^{3}$ Division of Nursing, Showa University Fujigaoka Hospital, Showa University, Yokohama, Japan
${ }^{4}$ Division of Physiology, School of Nursing and Rehabilitation Sciences, Showa University, Yokohama, Japan

\begin{abstract}
Background: Knee osteoarthritis (OA) is well known to be one of the most common joint disease in elderly people and characterized by pain, stiffness and loss of function in articulating joints, which develop slowly and worsen over time. Chondroitin sulfate (CS) and glucosamine hydrochloride are used for the treatment of OA and reported that these substances are favorably modify the clinical symptoms, especially pain, however, the therapeutic mechanisms of these substances are not fully understood. The present study was undertaken to examine the influence of CS on the production of periostin, which is one of the important molecules associated with OA development, by synoviocytes from an OA patient by an in vitro cell culture technique.

Methods: Synoviocytes $\left(1 \times 10^{5} \mathrm{cell} / \mathrm{ml}\right)$ were stimulated with $10.0 \mathrm{ng} / \mathrm{ml} \mathrm{IL-13}$ in the presence of various concentrations of CS. After $48 \mathrm{~h}$, periostin content in culture supernatants was examined by ELISA. We also examined the influence of CS on transcription factor, STAT6, activation and periostin mRNA expression in synoviocytes 12 and $24 \mathrm{~h}$ after IL-13 stimulation, respectively.

Results: Addition of CS into cell cultures caused the suppression of periostin production from synoviocytes induced by IL-13 stimulation through the inhibition of STAT6 activation and periostin mRNA expression. The minimum concentration of CS that caused significant suppression of periostin production, STAT6 activation and mRNA expression was $10.0 \mu \mathrm{g} / \mathrm{ml}$.

Conclusion: These results strongly suggest that the ability of CS to suppress periostin production from synoviocytes may account, at least in part, for the clinical efficacy of CS on OA.
\end{abstract}

\section{Introduction}

Knee osteoarthritis (OA) is well known to be one of the most common joint diseases and is a major cause of impaired mobility and disability in elderly people. $\mathrm{OA}$ is also accepted to be a disease characterized by pain, stiffness, swelling and deformation of the joints, which develop slowly and worsen over time [1,2]. Although $\mathrm{OA}$ is not life-threatening disease, it can deteriorate the quality of life and an economic burden through the clinical symptoms such as pain in affected joints during or after movement [3]. OA is characterized by progressive cartilage erosion mainly caused by the degradation and destruction of proteoglycan and collagen. It is also observed osteophyte formation and subchondral bone formation in diseased joints $[1,4]$. These histological and morphological changes are called tissue remodeling and triggered primarily by matrix metalloproteinases $[1,2,5]$.

Periostin is a $90-\mathrm{kDa}$ extracellular matrix protein originally isolated from a mouse osteoblast cell line and is a newly characterized matricellular protein functioned in the modulation of cell-matrix interactions rather than playing a direct structural role [6,7]. Periostin is well known to play essential roles in bone formation, cardiac development, tissue repair, tumor development and metastasis $[6,7$, 8]. It is also reported that periostin participates the development and the persistence of inflammatory diseases such as bronchial asthma, atopic dermatitis and allergic rhinitis [9-11]. Although the function of periostin on the development of OA is not fully understood, it is reported that synovial fluids obtained from OA patients contain much higher levels of periostin and its concentration gradually increases along with the progression of $\mathrm{OA}$ [2]. Immunohistochemical analysis of knee tissues obtained from patients with mild-to-moderate OA reveals the presence of periostin in chondrocytes and lacuna located near the erosive area [1]. In sever OA, the number of periostin positive chondrocytes is increased and the majority of matrix is lost, which is responsible for the development of many deep clefts [1]. These reports may suggest that periostin plays crucial roles in pathogenesis of OA.

Administration of nonsteroidal anti-inflammatory drugs, acetaminophen and intra-articular injection of either hyaluronic acid or corticosteroids are frequently used for the treatment of OA [12, 13]. Physical exercises, a prominent component of OA guidelines, are also used to prevent the development and the persistence of OA [12]. These treatments are well known to relieve pain and improve functionally, but not resolve the pathological changes once triggered $[12,14]$. On the other hand, there are much evidence that oral administration of glucosamine hydrochloride and chondroitin sulfate (CS), which are used as dietary supplements, into OA patients can favorably modify the clinical conditions of OA, especially pain and stiffness and joint swelling [13-16]. It is also reported that these two dietary supplements also exert the suppressive effects on joint space narrowing and osteoarthritis progression [17]. Although the clinical efficacy of these agents are considered to be owing to inhibition of

"Corresponding Author: Prof. Kazuhito Asano, Division of Physiology, School of Nursing and Rehabilitation Sciences, Showa University, 1865 Touka-Ichiba, Midori-Ku, Yokohama 226-8555, Japan; E-mail: asanok@med.showa-u.ac.jp

Citation: Tamaki D, Ishikawa S, Yamada A, Otaki A, Asano K (2016) Suppressive Activity of Chondroitin Sulfate on Periostin Production by Synoviocytes from Knee Osteoarthritis In Vitro. Int J Pharma Sci Res 3: 115. doi: https://doi. org/10.15344/2394-1502/2016/115

Copyright: (c) 2016 Tamaki et al. This is an open-access article distributed under the terms of the Creative Commons Attribution License, which permits unrestricted use, distribution, and reproduction in any medium, provided the original author and source are credited. 
Citation: Tamaki D, Ishikawa S, Yamada A, Otaki A, Asano K (2016) Suppressive Activity of Chondroitin Sulfate on Periostin Production by Synoviocytes from Knee Osteoarthritis In Vitro. Int J Pharma Sci Res 3: 115. doi: https://oi.org/10.15344/2394-1502/2016/115

Page 2 of 6

prostaglandin biosynthesis, which is responsible for development of pain and degradation of glycosaminoglycan, as well as hyaluronic acid synthesis in the joint, the precise therapeutic mechanisms of dietary supplements are not well defined [17]. The present study, therefore, was undertaken to examine the influence of dietary supplements on periostin production from synoviocytes through the choice of an in vitro cell culture technique and CS.

\section{Materials and Methods}

\section{Reagents}

CS, purchased from WAKO Pure Chemicals Co. Ltd. (Osaka, Japan) was firstly dissolved in phosphate-buffered saline at a concentration of $1.0 \mathrm{mg} / \mathrm{ml}$, sterilized by passing through $0.2 \mu \mathrm{m}$ filters and further diluted with Synoviocyte Growth (SG) Medium (Cell Applications, Inc., San Diego, CA, USA) at appropriate concentrations for experiments just before use. Recombinant human IL-13 was purchased from R \& D Systems, Inc. (Minneapolis, MN, USA) as preservative free pure powders. IL-13 was also dissolved in SG Medium, sterilized and stored at $-40^{\circ} \mathrm{C}$ until used. mRNA isolation kits (TaqMan Gene Expression Cells-to-CtTM) and real-time reverse transcription-polymerase chain reaction kits (RT-PCR; TaqMan Gene Expression Assays) were purchased from Applied Biosystems (Foster City, CA, USA).

\section{Cell culture}

Human synoviocytes (HFLS-OA) obtained from the inflamed synovial tissues of an OA patient (Cell Applications, Inc.) was suspended in SG Medium at a concentration of $1 \times 10^{5} \mathrm{cells} / \mathrm{ml}$ and used as a target cell. To examine the influence of IL-13 on periostin production from HFLS-OA, $1 \times 10^{5}$ cells $(1.0 \mathrm{ml})$ were introduced into 24-well culture plates in triplicate and stimulated with various concentrations of IL-13 in a final volume of $2.0 \mathrm{ml}$. After 24 to $72 \mathrm{~h}$, culture supernatants were collected and stored at $-40^{\circ} \mathrm{C}$ until used. In the case of examining the influence of $\mathrm{CS}$ on periostin production from HFLS-OA, $1 \times 10^{5}$ cells $(1.0 \mathrm{ml})$ were stimulated in triplicate with $10.0 \mathrm{ng} / \mathrm{ml} \mathrm{IL-13}$ in the presence of 5.0 to $50.0 \mu \mathrm{g} / \mathrm{ml} \mathrm{CS}$ in a final volume of $2.0 \mathrm{ml}$. After $48 \mathrm{~h}$, the culture supernatants were obtained and stored $-40^{\circ} \mathrm{C}$ until used. To prepare cells for examining the influence of CS on transcription factor, signal transducer and activator of transcription factor 6 (STAT6), activation and periostin mRNA expression in HFLS-OA after IL-13 stimulation, $1 \times 10^{5}$ cells $(1.0 \mathrm{ml})$ were stimulated in triplicate with $10.0 \mathrm{ng} / \mathrm{ml} \mathrm{IL}-13$ in the presence of 10.0 to $50.0 \mu \mathrm{g} / \mathrm{ml} \mathrm{CS}$ in a total volume of $2.0 \mathrm{ml}$ for 12 and $24 \mathrm{~h}$, respectively. In all experiments, CS was added to cell cultures $2 \mathrm{~h}$ before stimulation.

\section{Assay for periostin}

Periostin levels in culture supernatants was examined in duplicate by commercially available human periostin ELISA test kits (Phoenix Pharmaceuticals, Inc., Burlingame, CA, USA) according to the manufacturer's instructions. The minimum detectable level of this ELISA kit was $0.027 \mathrm{ng} / \mathrm{ml}$.

\section{Assay for transcription factor activation}

STAT6 activity in cultured cells was analyzed by examining the levels of phosphorylated STAT6 with ELISA test kits (Abcam plc., Cambridge, MA, USA) according to the manufacturer's recommended procedures.

\section{Assay for mRNA expression}

mRNA expression for periostin in cultured cells was examined by real-time RT-PCR. Total RNA was isolated from $1 \times 10^{5}$ cells using $50 \mu \mathrm{L}$ of a lysis solution (P/N4383583) after incubation for 2 $\mathrm{h}$ at $37^{\circ} \mathrm{C}$. Each sample of total RNA was subjected to RT using a $20 \mathrm{x}$ $\mathrm{RT}$ enzyme mix (P/N 4383585) and a $2 \mathrm{x}$ RT buffer (P/N43833586) with a T100 thermal cycler (Bio-Rad Co., Hercules, CA, USA). After the RT reaction, the cDNA templates were amplified by PCR using TaqMan Gene Expression Assays, PCR primers and RT master mix (P/N 4369016). Predesigned and validated gene-specific TaqMan Gene Expression Assays [18-20] were duplicated for quantitative RT-PCR, according to the manufacturer's protocols. PCR assays were conducted as follows: 10 min denaturation at $95^{\circ} \mathrm{C}, 40$ cycles of $15 \mathrm{~s}$, denaturation at $95^{\circ} \mathrm{C}$, and $1 \mathrm{~min}$ annealing and extension at $60^{\circ} \mathrm{C}$. Samples were analyzed using an ABI Prism 7900HT Fast RTPCR System (Applied Biosystems) [20, 21]. Relative quantification (RQ) studies [22] were prepared from collected data [threshold cycle numbers $(\mathrm{Ct})]$ with ABI Prism 7900HT Sequence-Detection System (SDS) software v. 2.3 (Applied Biosystems). The primers used for periostin mRNA expression was purchased from Applied Biosystems (ID: Hs01566734_m1) and 18S ribosomal RNA used as a housekeeping gene was also purchased from Applied Biosystems (ID: Hs99999901_s1).

\section{Statistical analysis}

Statistical significance between control and experimental groups was examined by ANOVA followed by Dunette's multiple comparison test. Data analysis was performed by using ANOVA for Mac (SPSS Inc., Chicago, IL, USA). The level of significance was considered at a $P$ value of less than 0.05 .

\section{Result}

\section{Influence of CS on periostin production from HFLS-OA after IL-13 stimulation}

The first experiments were undertaken to examine whether IL13 stimulation could induce periostin production from HFLS-OA. HFLS-OA $\left(1 \times 10^{5}\right.$ cells $\left./ \mathrm{ml}\right)$ was stimulated with $10.0 \mathrm{ng} / \mathrm{ml} \mathrm{IL-13}$ and periostin levels in culture supernatants were measured 24 to $72 \mathrm{~h}$ after stimulation. As shown in Figure 1A, periostin levels in culture supernatants were gradually increased, peaked at $24 \mathrm{~h}$ and plateaued $72 \mathrm{~h}$ after culture. The next experiments were designed to examine the dose response profile of IL-13 on periostin production from HFLS-OA. HFLS-OA ( $1 \times 10^{5}$ cells $\left./ \mathrm{ml}\right)$ was stimulated with various concentrations of IL-13 in triplicate and culture supernatants were collected $48 \mathrm{~h}$ after culture for measurement of periostin levels. As shown in Figure 1B, IL-13 stimulation at $5.0 \mathrm{ng} / \mathrm{ml}$ scarcely affected periostin production from HFLS-OA: periostin levels in experimental culture were nearly identical (not significant) to that in non-stimulated control. However, IL-13 at more than $10.0 \mathrm{ng} / \mathrm{ml}$ caused significant increase in periosin production from HFLS-OA (Figure 1B). The third experiments were undertaken to examine the influence of CS on periostin production from HFLS-OA after IL-13 stimulation. As shown in Figure 2, treatment of cells with CS at 10.0 $\mu \mathrm{g} / \mathrm{ml}$ significantly suppressed periostin production from HFLS-OA, which was increased by IL-13 stimulation. The data also showed that CS at more than $20.0 \mu \mathrm{g} / \mathrm{ml}$ completely inhibited the ability of HFLSOA to produce periostin: periostin levels in experimental culture supernatants were nearly identical (not significant) to that in nonstimulated control. 

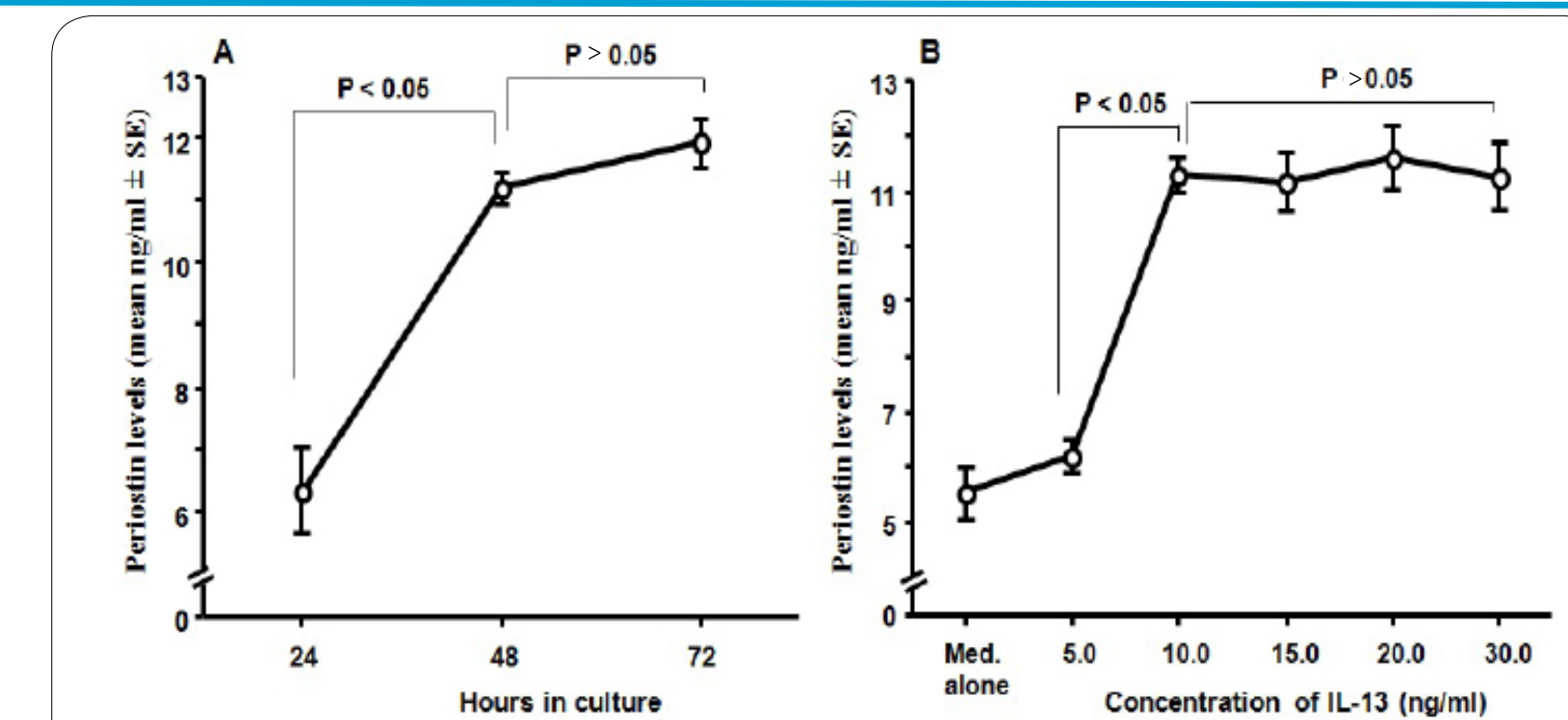

Figure 1 Influence of IL-13 on periostin production from HFLS-OA in vitro. Human synoviocytes from an OA patient (HFLS-OA) at 1 x $10^{5}$ cells $/ \mathrm{ml}$ were cultured with different concentrations of IL-13 for 24 to $72 \mathrm{~h}$. Concentration of periostin in culture supernatants was measured by ELISA. The results were expressed as the mean $\mathrm{ng} / \mathrm{ml} \pm \mathrm{SE}$ of triplicate cultures. A: Time course of IL-13-induced periostin production; B: Dose response profile of IL-13-induced periostin production; Med. alone: Medium alone. One representative experiment of two.

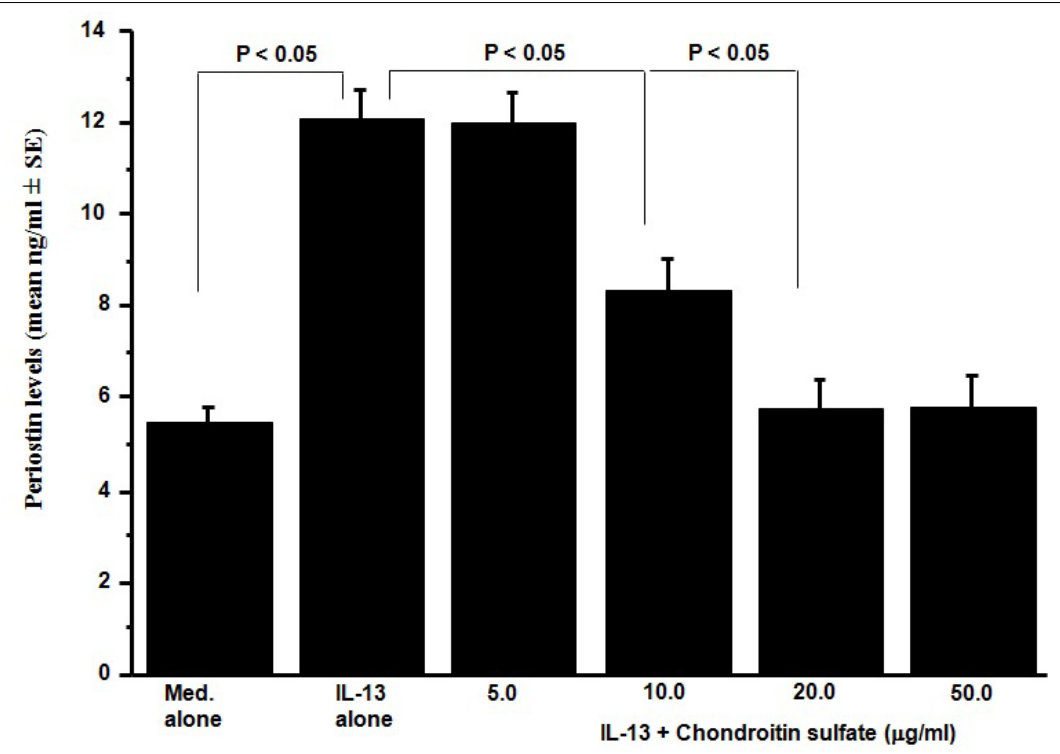

Figure 2: Influence of chondroitin sulfate (CS) on periostin production from HFLS-OA after IL-13 stimulation in vitro. Human synoviocytes from an OA patient (HFLS-OA) at $1 \times 10^{5}$ cells $/ \mathrm{ml}$ were cultured with $10.0 \mathrm{ng} / \mathrm{ml} \mathrm{IL-13} \mathrm{for} 48 \mathrm{~h}$ in the presence of various concentrations of CS. Periostin concentration in culture supernatants was measured by ELISA and the results were expressed as the mean $\mathrm{ng} / \mathrm{ml} \pm \mathrm{SE}$ of triplicate cultures. Med. alone: Medium alone. One representative experiment of two.

Influence of CS on STAT6 activation in HFLS-OA after IL-13 stimulation

The third experiments were designed to examine the influence of CS on transcription factor, STAT6, activation in HFLS-OA in response to IL-13 stimulation. HFLS-OA $\left(1 \times 10^{5}\right.$ cells $\left./ \mathrm{ml}\right)$ was stimulated with $10.0 \mathrm{ng} / \mathrm{ml} \mathrm{IL-13}$ in the presence of CS at concentrations of $5.0 \mu \mathrm{g} / \mathrm{ml}$ to $50.0 \mu \mathrm{g} / \mathrm{ml}$ and levels of phosphorylated STAT6 was measured 12 $\mathrm{h}$ after stimulation. As shown in Figure 3, treatment of cells with CS at more than $10.0 \mu \mathrm{g} / \mathrm{ml}$, but not $5.0 \mu \mathrm{g} / \mathrm{ml}$, significantly suppressed STAT6 activation, which was increased by IL-13 stimulation.
Influence of CS on periostin mRNA expression in HFLS-OA after IL-13 stimulation

The final experiments were carried out to examine the influence of CS on periostin mRNA expression in HFLS-OA after IL-13 stimulation. HFLS-OA ( 1 x $10^{5}$ cells $\left./ \mathrm{ml}\right)$ was stimulated with $10.0 \mathrm{ng} /$ $\mathrm{ml} \mathrm{IL-13}$ in the presence of CS at concentrations of $10.0 \mu \mathrm{g} / \mathrm{ml}$ to 50.0 $\mu \mathrm{g} / \mathrm{ml}$ for $24 \mathrm{~h}$ and periostin mRNA expression was examined by real time RT-PCR. As shown Figure 4, treatment of cells with CS at 10.0 $\mu \mathrm{g} / \mathrm{ml}$ caused significant suppression of periostin mRNA expression in HFLS-OA, which was increased by IL-13 stimulation. The data 
Citation: Tamaki D, Ishikawa S, Yamada A, Otaki A, Asano K (2016) Suppressive Activity of Chondroitin Sulfate on Periostin Production by Synoviocytes from Knee Osteoarthritis In Vitro. Int J Pharma Sci Res 3: 115. doi: https://doi.org/10.15344/2394-1502/2016/115

Page 4 of 6

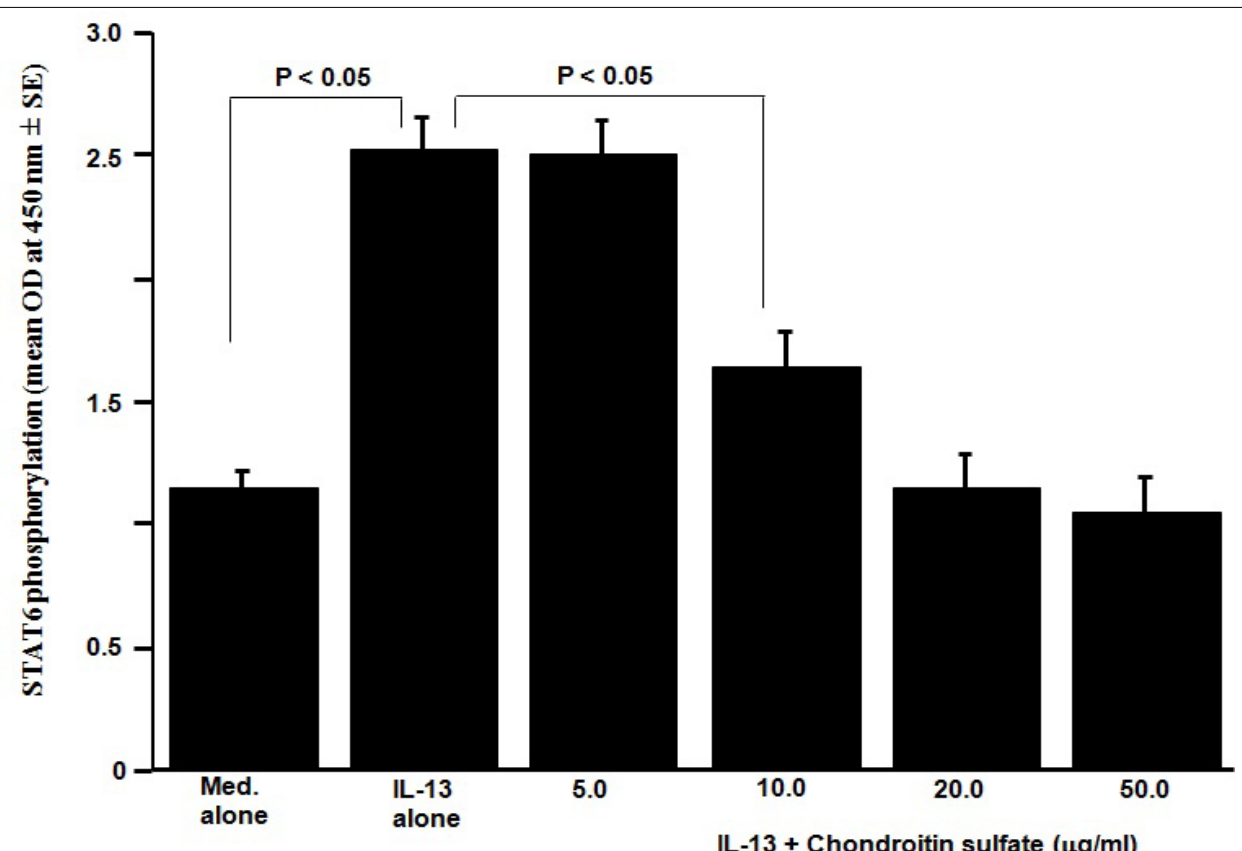

Figure 3 Influence of chondroitin sulfate (CS) on STAT6 activation after IL-13 stimulation in vitro. Human synoviocytes from an OA patient (HFLS-OA) at $1 \times 10^{5}$ cells/ml were cultured with $10.0 \mathrm{ng} / \mathrm{ml} \mathrm{IL-13}$ for $12 \mathrm{~h}$ in the presence of various concentrations of CS. STAT6 activation was measured by ELISA and the results were expressed as the mean optical density at $450 \mathrm{~nm} \pm$ SE of triplicate cultures. Med. alone: Medium alone. One representative experiment of two.

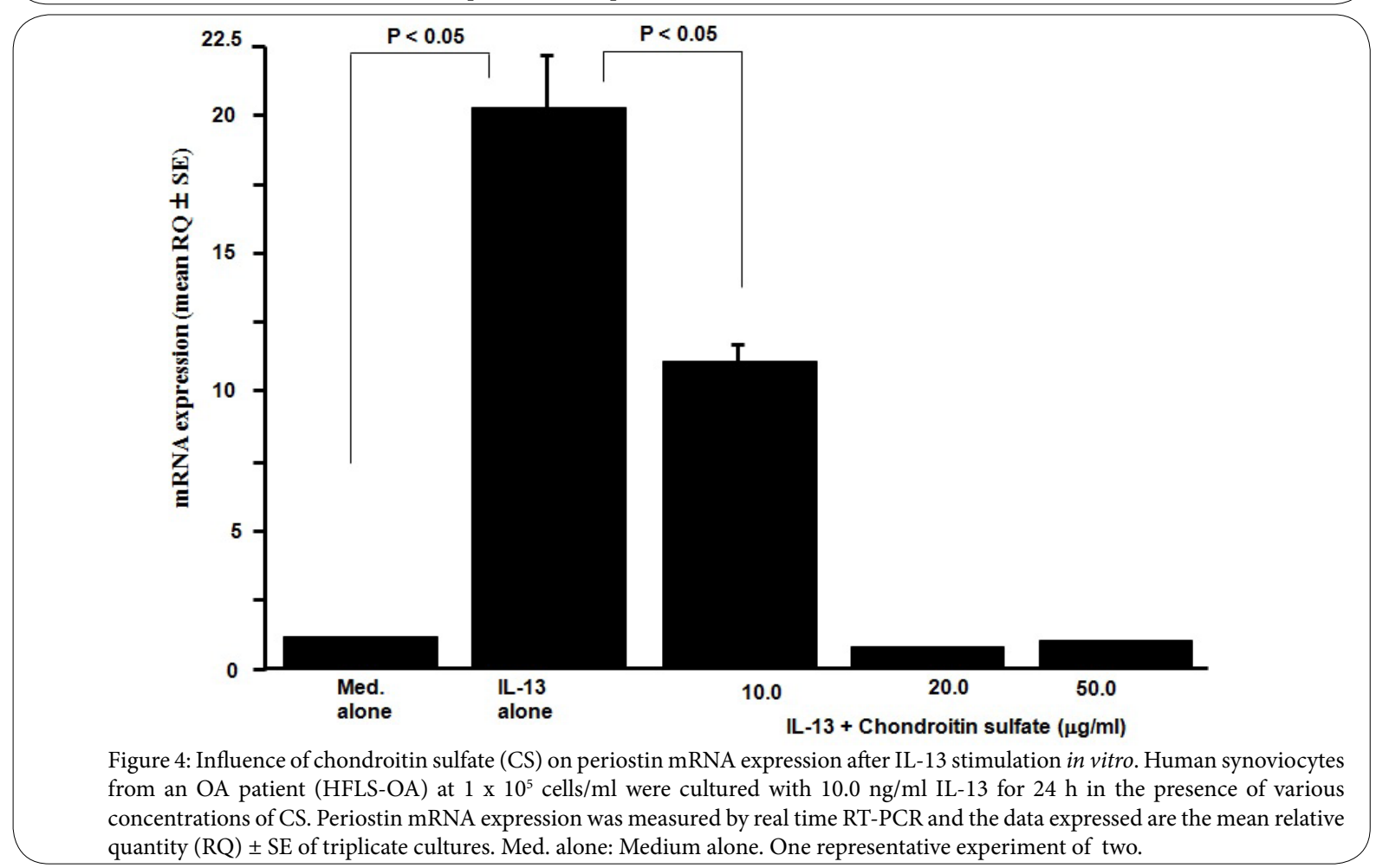

in Figure 4 also showed that CS at more than $20.0 \mu \mathrm{g} / \mathrm{ml}$ completely inhibited periostin mRNA expression in IL-13-stimulated HFLS-OA: mRNA levels in experimental cells were nearly identical to that in non-stimulated cells.

\section{Discussion}

OA is well known to be the major age-related public health problem resulting in pain, disability, and decreased quality of life $[1,2]$. It is also accepted that $\mathrm{OA}$ is characterized by progressive cartilage erosion and joint space narrowing, which follow alteration in the biomechanical and biochemical properties of the joints [4]. Since the precise mechanisms of OA progression is not fully understood, treatment is limited to symptomatic relief, especially pain or surgical replacement of the affected knee [1]. On the other hand, there is much evidence that oral administration of glucosamine hydrochloride and CS for long periods (e.g. approximately 1 year or more) into mild- to 
Citation: Tamaki D, Ishikawa S, Yamada A, Otaki A, Asano K (2016) Suppressive Activity of Chondroitin Sulfate on Periostin Production by Synoviocytes from Knee Osteoarthritis In Vitro. Int J Pharma Sci Res 3: 115. doi: https://oi.org/10.15344/2394-1502/2016/115

Page 5 of 6

moderate-, but not sever-, OA patients attenuate the progression of OA including joint space narrowing and joint swelling [13-17] However, the therapeutic mode of action of these two agents is not well defined. The present study, therefore, was undertaken to examine the influence of CS on the ability of synoviocytes to produce periostin, which is one of the important molecules in the development of OA [1, 2] by using an in vitro cell culture technique.

The present results clearly showed that treatment of synoviocytes from an OA patient with CS significantly inhibits periostin production from synoviocytes induced by IL-13 stimulation. The minimum concentration of CS that caused significant suppression was $10 \mu \mathrm{g} /$ $\mathrm{ml}$. After oral administration of $4000 \mathrm{mg} \mathrm{CS}$, which is recommended standard therapeutic dose of OA [23], into healthy male volunteers, plasma CS levels gradually increased, peaked at $12.73 \pm 4.69 \mu \mathrm{g} /$ $\mathrm{ml}$ with tmax (the time from administration at which the highest concentration in plasma is found) of $2.4 \pm 1.4$ hour, and decreased base line levels by $24 \mathrm{~h}$ [24]. It is also reported that approximately $10 \%$ to $20 \%$ of orally administered CS was absorbed and reached plateau levels at 10 to $15 \mu \mathrm{g} / \mathrm{ml}$ in plasma, when $1200 \mathrm{mg}$ CS was administered orally into healthy volunteers $[25,26]$. Judging from these reports, the findings of the present in vitro study may reflect the biological function of CS in vivo.

IL-13 is well known to be a multifunctional inflammatory cytokine mainly secreted from $\mathrm{CD} 4^{+} \mathrm{T}$ cells [27] and has been shown to be a useful biomarker to monitor the efficacy of treatment and the progression of OA $[2,27]$. IL-13 functions are mediated by a complex receptor system, including type I and type II receptor system [28] IL-13 first attaches to IL-13 receptor alpha (Ra) 1 subunit, which then leads to the activation of tyrosine kinases, tyrosine kinase 2 and janus kinase $2[28,29]$. Activation of these two kinases causes the phosphorylation and activation of transcription factor, especially STAT6, which is essential for mRNA expression for inflammatory mediators, including cytokines and periostin $[11,30]$. The second part of experiments, therefore, was undertaken to examine the possible mechanisms by which CS could inhibit periostin production from synoviocytes after IL-13 stimulation. The present data clearly showed the suppressive effects of CS at more than $10.0 \mu \mathrm{g} / \mathrm{ml}$ on STAT6 activation and periostin mRNA expression in synoviocytes, which were increased by IL-13 stimulation.

Periostin is reported to increase the expression of MMP-1, MMP3 , and MMP-13, which are thought to be essential collagenases for degradation of matrix in human OA cartilage [31], in chondrocytes [1] In addition to MMPs, periostin increases the ability of chondrocytes to produce IL-6 and IL-8, which are responsible for cartilage degradation through the enhancement of MMP production in chondrocytes and synoviocytes [1]. Furthermore, periostin increases the production of nitric oxide (NO), which is one of the important final effector molecules in the development of OA, from synoviocytes through the enhancement of NOS2, inducible NO synthase isoform, expression $[1,32]$. Together with these reports, the present results may be interpreted that oral administration of CS into OA patients suppresses periostin production from synoviocytes in response to IL13 stimulation and results in attenuation of OA progression.

\section{Conclusion}

The present results clearly demonstrated that CS at more than $10.0 \mu \mathrm{g} /$ $\mathrm{ml}$ exerts the inhibitory effects on IL-13-induced periostin production from human synoviocytes. These results strongly suggest that the ability of CS to suppress periostin production from synoviocytes may account, at least in part, for the clinical efficacy of CS on OA.

\section{Competing Interests}

The authors declare that they have no conflict of interest in this work.

\section{Author Contribution}

\section{Daisuke Tamaki}

Contribute to cell culture and sample collection.

Assay for periostin and STAT6 activation.

\section{Shintaro Ishikawa}

Assay for mRNA expression.

Asako Yamada and Amane Otaki

Data analysis, including statistical analysis (for data presented in: Figures 1-4).

Preparation of Figures 1-4.

Kazuhito Asano

Contribute to study design.

Participate in the methodological design and protocol.

Contribute to the entire manuscript writing.

\section{References}

1. Chijimatsu R, Kunugiza Y, Taniyama Y, Nakamura N, Tomita T, et al. (2015) Expression and pathological effects of periostin in human osteoarthritis cartilage. BMC Musculoskeletal Disorders 16: 215-226.

2. Ishikawa S, Asano K, Kusayanagi H, Takashima M, Yoshida N, et al. (2015) Influence of periostin on synovial fibroblasts in knee osteoarthritis. Chronic Dis Int 2: 1013.

3. Kotlarz H, Gunnarsson CL, Fang H, Rizzo JA (2009) Insurer and out-ofpocket costs of osteoarthritis in the US: evidence from national survey data. Arthritis Rheum 60: 3546-3553.

4. Lohmander LS (2000) What can we do about osteoarthritis? Arthritis Res 2: $95-100$.

5. Casagrande D, Stains JP, Murthi AM (2015) Identification of shoulder osteoarthritis biomarkers: comparison between shoulders with and without osteoarthritis. J Shoulder Elbow Surg 24: 382-390.

6. Horiuchi K, Amizuka N, Takeshita S, Takamatsu H, Katsuura M, et al (1999) Identification and characterization of a novel protein, periostin with restricted expression to periosteum and periodontal ligament and increased expression by transforming growth factor beta. $\mathrm{J}$ Bone Miner Res 14: 1239-1249.

7. Conway SJ, Izuhara K, Kudo Y, Litvin J, Markwald R, et al. (2014) The role of periostin in tissue remodeling across health and disease. Cell Mol Life Sci 71: 1279-1288.

8. Takeshita S, Kikuno R, Tezuka K, Amann E (1993) Osteoblast-specific factor 2: cloning of a putative bone adhesion protein with homology with the insect protein fasciclin I. Biochem J 294 : 271-278.

9. Uchida M, Shiraishi H, Ohta S, Arima K, Taniguchi K, et al. (2012) Periostin, a matricellular protein, plays a role in the induction of chemokines in pulmonary fibrosis. Am J Respir Cell Mol Biol 46: 677-686.

10. Ohta N, Ishida A, Kurakami K, Suzuki Y, Kakehata S, et al. (2014) Expressions and roles of periostin in otolaryngological diseases. Allergol Int 63: 171-180.

11. Furuta A, Asano K, Suzuki T, Mizuyoshi T, Asano M, et al. (2015) Suppressive activity of macrolide antibiotics on periostin production from nasal cells in vitro and in vivo. Chronic Dis Int 2: 1012. 
Citation: Tamaki D, Ishikawa S, Yamada A, Otaki A, Asano K (2016) Suppressive Activity of Chondroitin Sulfate on Periostin Production by Synoviocytes from Knee Osteoarthritis In Vitro. Int J Pharma Sci Res 3: 115. doi: https://oi.org/10.15344/2394-1502/2016/115

Page 6 of 6

12. Veronesi F, Fini M, Giavaresi G, Ongaro A, Mattei M, et al. (2015) Experimentally induced cartilage degeneration treated by pulsed electromagnetic field stimulation; an in vitro study on bovine cartilage. BMC Musculoskeletal Disorders 16: 308.

13. Provenza JR, Shinjo SK, Silva JM, Peron CRGS, Rocha FA (2015) Combined glucosamine and chondroitin sulfate, once or three times daily, provides clinically relevant analgesia in keen osteoarthritis. Clin Rheumato 34: 1455-1462.

14. Gallagher B, Tjoumakaris FP, Harwood MI, Good RP, Ciccotti MG, et al (2015) Chondroprotection and the prevention of osteoarthritis progression of the knee: a systematic review of treatment agents. Am J Sports Med 43: 734-744.

15. Henrotin Y, Marty M, Mobasheri A (2014) What is the current status of chondroitin sulfate and glucosamine for the treatment of knee osteoarthritis? Maturitas 78: 184-187.

16. Percope de Andrade MA, Campos TV, Abreu-E-Silva GM (2015) Supplementary methods in the nonsurgical treatment of osteoarthritis. Arthroscopy 31: 785-792.

17. Hochberg MC, Martel-Pelletier J, Monfort J, Moller I, Castillo JR, et al (2015) Combined chondroitin sulfate and glucosamine for painful knee osteoarthritis: a multicenter, randomized, double-blind, non-inferiority trial versus celecoxib. Ann Rheum Dis 75: 37-44.

18. Swartzman E, Shannon M, Lieu P, Chen SM, Mooney C, et al. (2010) Expanding applications of protein analysis using proximity ligation and qPCR. Methods 50: S23-26.

19. Keter FK, Kanyanda S, Lyantagaye SS, Darkwa J, Rees DJ, et al. (2008) In vitro evaluation of dichloro-bis(pyrazole)palladium(II) and dichlorobis(pyrazole)platinum(II) complexes as anticancer agents. Cancer Chemother Pharmacol 63: 127-138.

20. Barbacioru CC, Wang Y, Canales RD, Sun YA, Keys DN, et al. (2006) Effect of various normalization methods on Applied Biosystems expression array system data. BMC Bioinformatics 7: 533.

21. Martínez A, Sánchez-Lopez M, Varadé J, Mas A, Martín MC, et al. (2007) Role of the MHC2TA gene in autoimmune diseases. Ann Rheum Dis 66 325-329.

22. Kósa JP, Kis A, Bácsi K, Balla B, Nagy Z, et al. (2011) The protective role of bone morphogenetic protein-8 in the glucocorticoid-induced apoptosis on bone cells. Bone 48: 1052-1057.

23. Volpi $N$ (2003) Oral absorption and bioavailability of ichthyic origin chondroitin sulfate in healthy male volunteers. Osteoarthritis Cartilage 11: 433-441.

24. Volpi N (2002) Oral bioavailability of chondroitin sulfate (Condrosulf) and its constituents in healthy male volunteers. Osteoarthritis Cartilage 10: 768 777.

25. Kubo M, Ando K, Mimura T, Matsusue Y, Mori K (2009) Chondroitin sulfate for the treatment of hip and knee osteoarthritis: current status and future trends. Life Sci 85: 477-483.

26. Volpi $N$ (2010) About oral absorption and human pharmacokinetics of chondroitin sulfate. Osteoarthritis Cartilage 18: 1104-1105.

27. Tsuchida A, Beekhuizen M, Hart MC, Radstake T, Dhert W, et al. (2014) Cytokine profiles in the joint depend on pathology, but are different between synovial fluid, cartilage tissue and cultured chondrocytes. Arthritis Res Ther 16: 441.

28. Oh CK, Geba GP, Molfino N (2010) Investigational therapeutics targeting the IL-4/IL-13/STAT- 6 pathway for the treatment of asthma. Eur Respir Rev 19: 46-54.

29. Chiba Y, Goto K, Misawa M (2012) Interleukin-13-induced activation of signal transducer and activator of transcription 6 is mediated by an activation of Janus kinase 1 in cultured human bronchial smooth muscle cells. Pharmacol Rep 64: 454-458.

30. Hakuno D, Kimura N, Yoshioka M, Mukai M, Kimura T, et al. (2010) Periostin advances atherosclerotic and rheumatic cardiac valve degeneration by inducing angiogenesis and MMP production in humans and rodents. $\mathrm{J}$ Clin Invest 120: 2292-2306.

31. Davidson RK, Waters JG, Kevorkian L, Darrah C, Cooper A, et al. (2006) Expression profiling of metalloproteinases and their inhibitors in synovium and cartilage. Arthritis Res Ther 8: R124.

32. Ohta C, Yamada A, Yufune K, Asano K (2016) Suppressive Activity of Glucosamine Hydrochloride on Nitric Oxide Production from Synoviocytes In Vitro. Int J Pharma Sci Res 3: 111. 